\title{
A longitudinal study of post-haemorrhagic ventricular dilatation in the newborn
}

\author{
MALCOLM I LEVENE AND DAVID R. STARTE \\ Department of Paediatrics and Neonatal Medicine, Institute of Child Health, Hammersmith Hospital, \\ London
}

SUMMARY Two hundred and two consecutive admissions to a regional neonatal unit were scanned by real-time ultrasound. Sixty-eight (34\%) infants had intracranial haemorrhage, $39(57 \%)$ of whom were scanned repeatedly until they were at least 30 days old. Fifteen infants showed some degree of ventricular dilatation. Four had transient dilatation with complete recovery without any form of treatment (group 1), 7 showed persistent but non-progressive dilatation with no treatment (group 2), 3 had rapidly progressive hydrocephalus (group 3), and 1 had cerebral atrophy (group 4). Occipitofrontal head circumference was also followed sequentially from birth and was not abnormal in groups 1 and 2, but abnormal rates of head growth were seen in groups 3 and 4 . It is concluded that after intracranial haemorrhage only a small proportion of infants develop frank hydrocephalus, but ventricular dilatation of some degree is common and may require no treatment.

Hydrocephalus occurring after intracranial haemorrhage has been recognised for more than 130 years. ${ }^{1}$ Until recently obstruction to the ventricular system in the preterm infant after intraventricular haemorrhage (IVH) had been little studied. The introduction of computerised tomography (CT), and more recently real-time ultrasound, has made possible the systematic investigation of IVH and subsequent hydrocephalus. This study describes the incidence of ventricular dilatation after intracranial haemorrhage and the subsequent natural history of this condition in 202 consecutively-born neonates.

\section{Methods}

All infants admitted to the neonatal unit at Hammersmith Hospital during a period of 10 months from 1 November 1979 were scanned sequentially with a Kranzbühler ADR linear array real-time ultrasound machine. ${ }^{2}$ Duration of gestation was calculated according to maternal dates and gestational assessment. ${ }^{3}$ Infants were scanned at least weekly and often daily while in the neonatal unit, and thereafter at all follow-up clinic attendances.

Maximal occipitofrontal head circumference was measured weekly on all 202 infants. A flexible metal or glass fibre-coated linen tape was used, and each infant was measured by one person only (MIL or
DRS) during his stay in the neonatal unit. The results were plotted on composite occipitofrontal circumference charts which used the longitudinal growth data of Largo and Duc ${ }^{4}$ for infants of 32 weeks' gestational age and older, and similar data prepared by one of us (DRS) from two west London hospital populations of infants under 32 weeks' maturity.

Ultrasound scans were performed (by MIL) in an axial plane through the temporoparietal region using a $5 \mathrm{MHz}$ transducer and the methods for diagnosis of intercranial haemorrhage have been previously reported. ${ }^{2}$ Measurement was made of the distance between the lateral ventricle and the falx, this distance being referred to as the ventricular index. In addition, transfontanelle coronal scans of the body of the lateral ventricle were also performed with a $7 \mathrm{MHz}$ transducer. A measurement of less than $6 \mathrm{~mm}$ from the floor of the lateral ventricle to its roof at this point was considered to be normal. An infant was judged to have dilated ventricles if the ventricular index measurement showed an increase from a normal figure to one above the 97th centile for its gestational age on growth charts of the lateral ventricle, ${ }^{5}$ or if the distance from the roof to the floor of the lateral ventricle exceeded $6 \mathrm{~mm}$. Both these measurements could be made rapidly and with little difficulty. 


\section{Results}

Intracranial haemorrhage was diagnosed on ultrasound examination in $68(34 \%)$ infants. In $13(6 \%)$ infants the diagnosis of IVH could not be made with certainty because of technical difficulties. Only preterm infants or ones who were ill were admitted to our neonatal unit, and Table 1 shows the distribution of intracranial haemorrhage according to gestational age for this highly selected population. In all but 2 of these babies the origin of the bleeding was from the lateral ventricles. Subdural haemorrhage was diagnosed on ultrasound scanning in one patient (Case 14), and in another term infant, a large subarachnoid haemorrhage was diagnosed on the clinical findings of neck stiffness in conjunction with uniformly stained spinal fluid without IVH on ultrasound (Case 9).

Thirty-nine of the surviving infants with intracranial haemorrhage were seen at age 30 days or more. Fifteen ( $39 \%$ ), of these 39 survivors developed dilated ventricles, and all but 3 were 34 weeks or less, 8 of whom were 30 weeks or less (Table 2). None of the infants with dilated ventricles received any treatment except for 3 with excessively rapid head growth and bulging fontanelle in whom ventricular shunts were inserted. Fig. 1 summarises the fate of the 202 infants in the study.

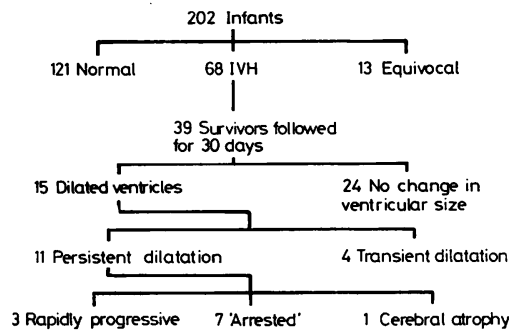

Fig. 1 Outcome of the 202 infants in study group.

Table 1 Incidence of IVH and post-haemorrhagic ventricular dilatation by gestational age in 202 infants

\begin{tabular}{lcccc}
\hline $\begin{array}{l}\text { Gestational age } \\
\text { (weeks) }\end{array}$ & $\begin{array}{l}\text { Definite } \\
\text { IVH }\end{array}$ & Deaths & $\begin{array}{l}\text { Infants } \\
\text { followed } \\
\text { for }>30 \\
\text { days }\end{array}$ & $\begin{array}{l}\text { Survivors } \\
\text { of definite } \\
\text { IVH } \\
\text { followed }\end{array}$ \\
\cline { 2 - 5 } & & & & No (\%) \\
\hline $26-28(n=17)$ & 9 & 10 & 6 & $6(67)$ \\
$29-30(n=34)$ & 17 & 5 & 23 & $13(76)$ \\
$31-32(n=32)$ & 8 & 2 & 15 & $3(38)$ \\
$33-34(n=41)$ & 14 & 1 & 21 & $9(64)$ \\
$35-36(n=28)$ & 9 & 2 & 11 & $4(44)$ \\
$37-38(n=14)$ & 1 & 2 & 1 & $0(0)$ \\
$39-40(n=30)$ & 10 & 4 & 9 & $4(40)$ \\
$41-42(n=6)$ & 0 & 1 & 1 & $0(0)$ \\
Total & $68(34 \%)$ & $27(13 \%)$ & $87(43 \%)$ & $39(57)$ \\
\hline
\end{tabular}

Four patterns of ventricular enlargement were noted: group $1(n=4)$ showed transient dilatation with complete resolution, group $2(n=7)$ showed persistent but non-progressive dilatation, group 3 $(n=3)$ showed progressive dilatation of ventricles

Table 2 Details of infants with ventricular dilatation

\begin{tabular}{|c|c|c|c|c|c|c|}
\hline Case & $\begin{array}{l}\text { Gesta- } \\
\text { tional } \\
\text { age } \\
\text { (weeks) }\end{array}$ & $\begin{array}{l}\text { Birth- } \\
\text { weight } \\
(g)\end{array}$ & $\begin{array}{l}\text { Age at } \\
\text { bleed } \\
\text { (days) }\end{array}$ & $\begin{array}{l}\text { Interval } \\
\text { between } \\
\text { IVH and } \\
\text { dilatation } \\
\text { (in days) }\end{array}$ & $\begin{array}{l}\text { Type of } \\
\text { haemor- } \\
\text { rhage }\end{array}$ & Outcome \\
\hline 1 & 30 & 1230 & 3 & $\begin{array}{l}\text { Normal } \\
\text { at } 43, \\
\text { dilated a } \\
180\end{array}$ & IVH & $\begin{array}{l}\text { Persistently dilated, } \\
\text { but non-progres- } \\
\text { sive }\end{array}$ \\
\hline 2 & 27 & 770 & 2 & $?$ & IVH & $\begin{array}{l}\text { Gross hydro- } \\
\text { cephalus. Died } \\
\text { before shunt in- } \\
\text { serted }\end{array}$ \\
\hline 3 & 29 & 1110 & 1 & 10 & IVH & $\begin{array}{l}\text { Complete resolution } \\
\text { by } 32 \text { nd day }\end{array}$ \\
\hline 4 & 34 & 2500 & 2 & 39 & IVH & $\begin{array}{l}\text { Poor head growth. } \\
\text { Cerebral atrophy }\end{array}$ \\
\hline 5 & 28 & 1270 & 5 & 24 & IVH & $\begin{array}{l}\text { Complete resolution } \\
\text { by } 34 \text { th day }\end{array}$ \\
\hline 6 & 27 & 920 & 2 & 15 & IVH & $\begin{array}{l}\text { Complete resolution } \\
\text { by } 25 \text { th day }\end{array}$ \\
\hline 7 & 30 & 1370 & 3 & 33 & IVH & $\begin{array}{l}\text { Persistently dilated } \\
\text { but non-progres- } \\
\text { sive }\end{array}$ \\
\hline 8 & 29 & 1150 & 2 & 40 & IVH & $\begin{array}{l}\text { Persistently dilated } \\
\text { but non-progres- } \\
\text { sive }\end{array}$ \\
\hline 9 & 40 & 4075 & 10 & 5 & SAH & $\begin{array}{l}\text { Persistently dilated } \\
\text { but non-progres- } \\
\text { sive }\end{array}$ \\
\hline 10 & 34 & 2150 & 4 & 3 & IVH & $\begin{array}{l}\text { Gross hydro- } \\
\text { cephalus, shunt in- } \\
\text { serted } 26 \text { th day }\end{array}$ \\
\hline 11 & 29 & 1030 & 3 & 10 & IVH & $\begin{array}{l}\text { Persistently dilated } \\
\text { but non-progres- } \\
\text { sive }\end{array}$ \\
\hline 12 & 40 & 3540 & 1 & 1 & IVH & $\begin{array}{l}\text { Gross hydro- } \\
\text { cephalus, shunt in- } \\
\text { serted 52nd day }\end{array}$ \\
\hline 13 & 33 & 1830 & 1 & 11 & IVH & $\begin{array}{l}\text { Persistently dilated } \\
\text { but non-progres- } \\
\text { sive }\end{array}$ \\
\hline 14 & 40 & 4210 & 42 & 34 & $\begin{array}{l}\text { Sub- } \\
\text { dural }\end{array}$ & $\begin{array}{l}\text { Persistently dilated } \\
\text { but non-progres- } \\
\text { sive }\end{array}$ \\
\hline 15 & 32 & 2110 & $5-8$ & 3 & IVH & $\begin{array}{l}\text { Complete resolution } \\
\text { by } 71 \text { days }\end{array}$ \\
\hline
\end{tabular}

SAH = subarachnoid haemorrhage.

Table 3 Comparison of outcome of IVH with regard to dilated ventricles in two studies; that of Levene and Starte (no treatment) and Papile et al. (regular lumbar puncture taps)

\begin{tabular}{lll}
\hline & $\begin{array}{l}\text { Levene and Starte } \\
(n=68 I V H)\end{array}$ & $\begin{array}{l}\text { Papile et al.22 } \\
(n=63 \mathrm{IVH})\end{array}$ \\
\hline IVH sequentially followed & 39 & 28 \\
Dilated ventricles & 15 & 15 \\
Transient dilatation & 4 & 6 \\
Arrested dilatation & 8 & 5 \\
Hydrocephalus & 3 & 4 \\
\hline
\end{tabular}




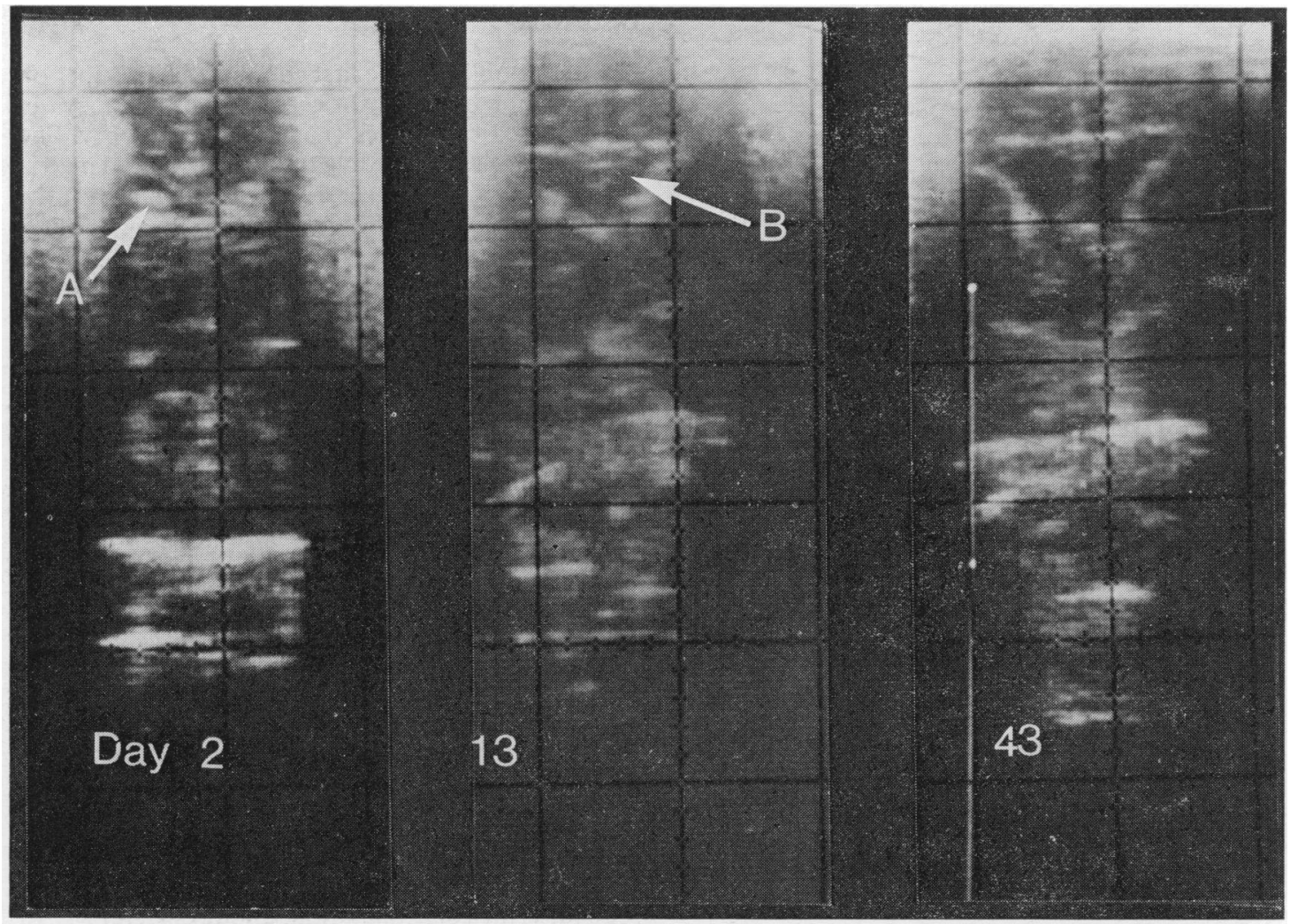

$\mathrm{A}=$ germinal matrix haemorrhage, $\mathrm{B}=$ lateral ventricles.

Fig. 2 Coronal transfontanelle ultrasound scans $(7 \mathrm{MHz})$ showing persistent but non-progressive ventricular dilatation in Case 13. Age in days indicated.

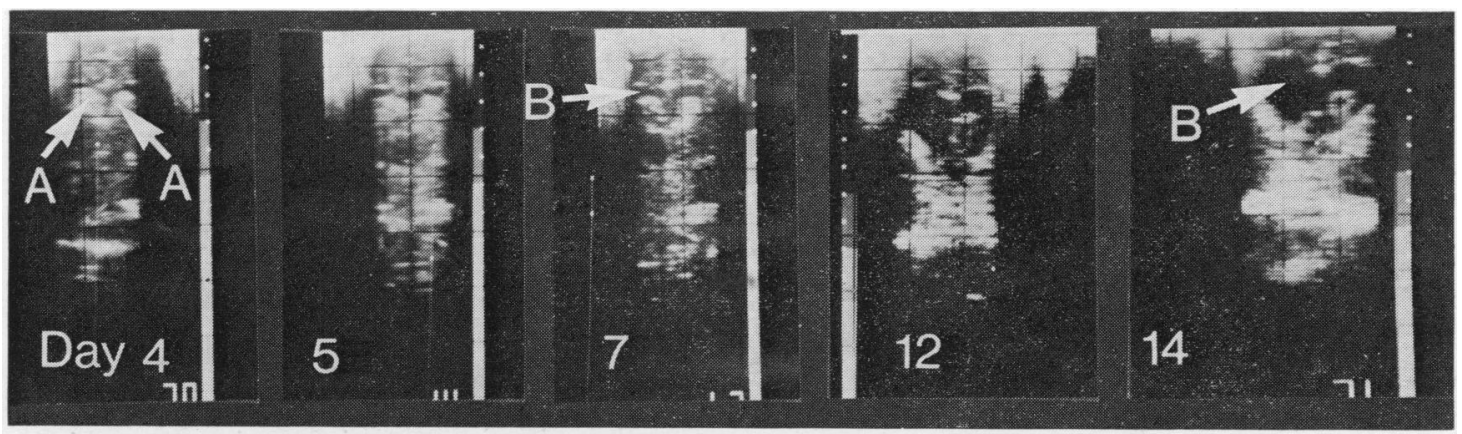

$\mathrm{A}=$ germinal matrix haemorrhage, $\mathrm{B}=$ lateral ventricles.

Fig. 3 Coronal transfontanelle ultrasound $(7 \mathrm{MHz})$ showing progressive hydrocephalus in Case 10. Age in days indicated.

shortly after haemorrhage requiring shunting, and group $4(n=1)$ showed ventricular dilatation but poor head growth because of cerebral atrophy. Figs 2 and 3 show examples of scans on infants with 'arrested' and progressive hydrocephalus. The pat- tern of serial occipitofrontal head circumference measurements in these cases is shown in Figs 4 to 6. In the one baby in group 4, sudden and unexpected death occurred at 4 months and cerebral atrophy was confirmed at necropsy. 


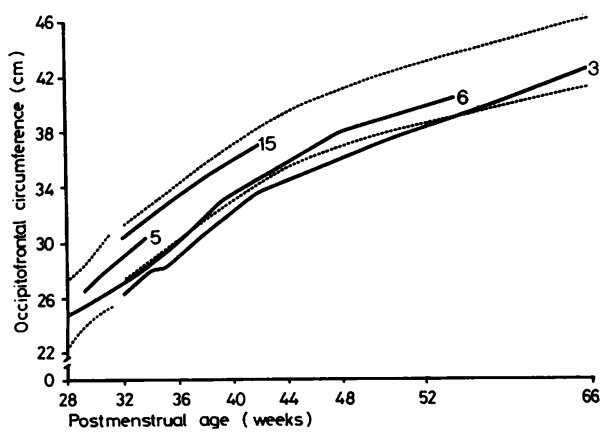

Fig. 4 Occipitofrontal head circumference in 4 infants with transiently dilated ventricles.

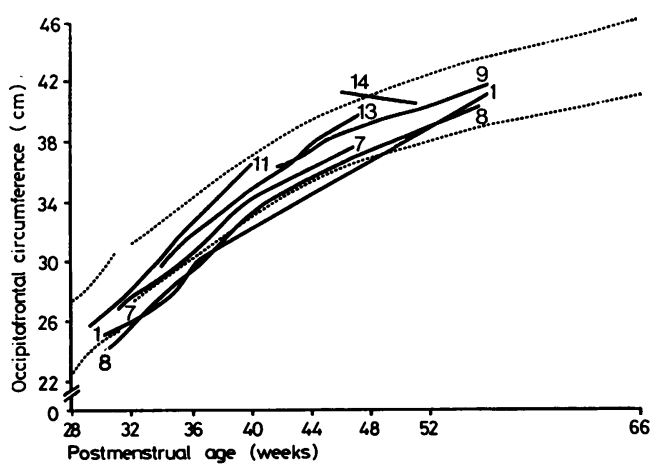

Fig. 5 Occipitofrontal head circumference in 7 infants with persistent but non-progressive ventricular dilatation.

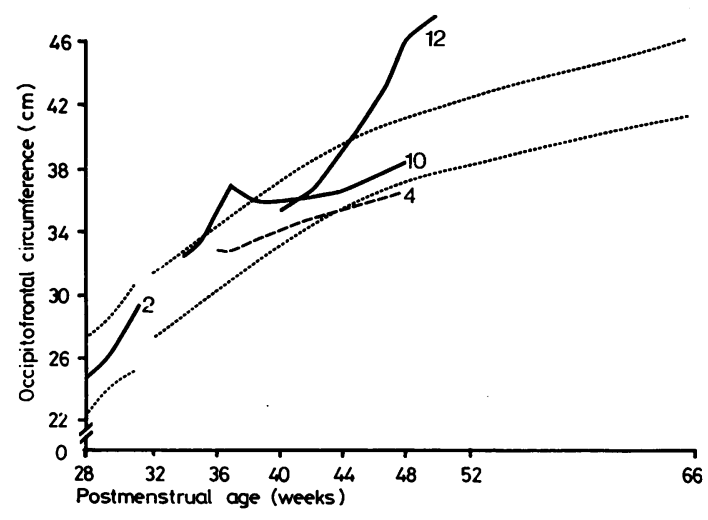

Fig. 6 Occipitofrontal head circumference in 3 infants with rapid onset hydrocephalus (solid lines) and one infant with cerebral atrophy (broken line).

\section{Discussion}

Larroche published the first comprehensive paper on post-haemorrhagic hydrocephalus of infancy in $1972,{ }^{6}$ based on 9 cases examined at necropsy. She showed the site of bleeding to be the germinal matrix in 6 preterm infants and to be confined to the subarachnoid or subdural spaces in 3 infants. Obstruction occurred either in the posterior fossa or the aqueduct of Sylvius. Lorber and Bhat ${ }^{7}$ found a post-haemorrhagic aetiology in $3 \%$ of 588 hydrocephalic infants. A follow-up study from Toronto 8 cited a $10 \%$ incidence of hydrocephalus in 73 survivors of mechanical ventilation of birthweight under $1501 \mathrm{~g}$.

Introduction of CT scanning now allows accurate diagnosis of IVH and early detection of hydrocephalus. ${ }^{9-12}$ In a prospective study of 100 infants of birthweights $1500 \mathrm{~g}$ and below, 8 of 14 survivors of IVH became hydrocephalic. ${ }^{12}$ Krishnamoorthy et $a .^{13}$ also reported 8 cases of hydrocephalus among 15 survivors of intracranial haemorrhage, but only 5 of them required shunts. In our study, $3(8 \%)$ of the 39 survivors of intracranial haemorrhage developed rapidly progressing hydrocephalus requiring shunting, but considerably more $(31 \%)$ babies than this showed some degree of ventricular dilatation.

Subependymal haemorrhage is the most common cause of neonatal intracranial bleeding with subsequent ventricular dilatation, and occurred in 12 of the 15 infants reported here. This type of lesion can be distinguished from other forms of intraventricular haemorrhage by transfontanelle coronal ultrasound scans $^{2}$ and constitutes a homogeneous pathophysiological group. Three term infants were included in this study in whom the intracranial haemorrhage arose from subarachnoid, subdural, and choroid plexus bleeds respectively. The aetiology of such conditions is different from that of subependymal haemorrhage and reflects a wider range of pathophysiological events leading to the haemorrhagic lesion.

In order to assess the true incidence of dilated lateral ventricles, enlargement beyond a normal range must be shown. We have determined such a range of ventricular size for various gestational ages, ${ }^{5}$ thus allowing those infants in whom this is more than 2 standard deviations (SDs) above the mean to be identified. On this basis, infants with transiently or permanently dilated ventricles may be recognised even if head growth is not abnormal.

Infants in group 1 showed some dilatation of the body of the lateral ventricles some days after the onset of haemorrhage. The ventricles remained dilated for some time before complete and spon- 
taneous resolution occurred without treatment. Similar transient dilatation has also been detected by CT scanning in $6(12 \%)$ of 49 survivors with intraventricular haemorrhage. ${ }^{14}$ This compares with a $6 \%$ incidence of transient dilatation in our study. It has been recognised for many years that hydrocephalus may arrest with or without treatment. In our study 8 infants came into this category of persistent but non-progressive dilatation. From reports it is difficult to know how commonly this occurs. Some surgeons insert ventricular shunts in all children shown to have dilated ventricles; ${ }^{15}$ other cases may be missed unless regular scanning is undertaken. Arrest of hydrocephalus occurring in small numbers of preterm infants without shunting has been frequently reported. ${ }^{10131617}$ It is likely that the paucity of longitudinal studies measuring ventricular size sequentially in a cohort of infants at risk of IVH accounts for the apparent rarity of progressive ventricular dilatation.

Rapid head growth is not apparent in infants with persistently dilated ventricles so that the condition may be clinically unsuspected. Infants in groups 1 and 2 showed no abnormality in the rate of head growth on longitudinal occipitofrontal circumference charts. Infants in group 3 showed rapid increase in head size crossing centile lines in an upwards direction; all had wide sutures, bulging fontanelles, and a growth velocity more than 2 SDs above the mean for their gestation. One infant in this group died of necrotising enterocolitis before a valve could be inserted and massive hydrocephalus was found at necropsy. Ventricular enlargement shown by ultrasound in the presence of failing head growth suggests cerebral atrophy and this was confirmed at necropsy in one case.

There is little agreement about the management of infants with dilated ventricles. Those in whom there is rapid head growth, a bulging fontanelle, and splayed sutures may receive ventricular shunts. ${ }^{7}$ If the infant is frail, medical management with glycerol $^{18}$ or isosorbide ${ }^{7}$ has been undertaken. and other treatments-such as regular cerebrospinal fluid $\operatorname{taps}^{1319}$ or compressive head wrappings ${ }^{20} 21$ - have been used in some centres. Those infants shown to have dilated ventricles on ultrasound before a rapid increase in head size has occurred may also be treated by these methods, and arrest of the hydrocephalus incorrectly ascribed to treatment when ventricular dilatation might have been transient or subject to spontaneous arrest.

Recently Papile et al. ${ }^{22}$ reported a study of 28 low birthweight infants surviving severe IVH, of whom $15(54 \%)$ were shown by sequential CT scanning to have developed dilated ventricles; serial lumbar punctures were successfully performed on twelve.
Six had transient dilatation with complete resolution to normal ventricular size, 5 had persistently dilated ventricles, and 4 required shunting for progressive ventricular dilatation. Unfortunately, that study was not controlled and it is interesting to note how similar the proportion of infants in each group is to the figures in our study (Table 3), which suggests that the outcome in those infants receiving regular lumbar puncture taps would be the same had they remained untreated, and that they represent the natural history of this condition.

The validity of undertaking treatment is most questionable in the sorts of infants similar to those in groups 1 and 2. These babies in our study received no treatment because the risks of shunting and lumbar puncture or other procedures were considered to outweigh the potential advantages of treatment. Follow-up data must be considered in evaluating the efficacy of treatment versus nontreatment of this condition. Although our follow-up results are incomplete, the initial impression is that compared with matched infants with IVH but without ventricular dilatation, they are not functioning as well. However, this may be due to the extent of the initial haemorrhage as much as to ventricular size. In our opinion, to resolve adequately the question of whether and when to treat nonprogressive ventricular dilatation, a controlled clinical trial must be undertaken and neurological outcome be closely monitored.

Experimental studies in animals in whom sudden obstructive hydrocephalus has been induced show severe pathological changes in the ependyma and surrounding brain. ${ }^{23-25}$ Weller and Shulman ${ }^{26}$ have suggested that in hydrocephalus there is a crucial period of white matter oedema during which slow but irreversible brain damage occurs. Rowlat ${ }^{27}$ however, could find no evidence for actual destruction of white matter in the brains of 11 patients with some degree of ventricular dilatation (although only 2 were children). Long-term neurological handicap may be related to the primary condition (for example IVH) which causes the hydrocephalus rather than to the dilated ventricle per se.

Finally, it is apparent that real-time ultrasound provides a convenient, non-invasive, safe, and reliable method of measuring ventricular size. The risk of transportation, sedation, and radiation exposure inherent in CT scanning should make ultrasound the method of choice to diagnose and follow posthaemorrhagic hydrocephalus.

We thank Professor Victor Dubowitz, Dr Pamela Davies, and Dr Michael Silverman for assistance, advice, and permission to study their patients, the nurses of the neonatal unit for co-operation, Miss A 
Smith for secretarial help, and the Department of Medical Illustration, Royal Postgraduate Medical School, for the photographs.

M I L was supported by the Wellcome Trust and D R S by the Spastics Society.

\section{References}

1 West C. Lectures on the diseases of infancy and childhood. London: Longmans, 1848.

2 Levene M I, Wigglesworth J S, Dubowitz V. Cerebral structure and intraventricular haemorrhage in the neonate: a real-time ultrasound study. Arch Dis Child 1981 ; 56: 416-24.

3 Dubowitz L M S, Dubowitz V, Goldberg C. Clinical assessment of gestational age in the newborn infant. $J$ Pediatr 1970; 77: 1-10.

4 Largo R H, Duc G. Head growth and changes in head configuration in healthy preterm and term infants during the first six months of life. Helv Paediatr Acta 1977; 32: 431-42.

5 Levene M I. Measurement of the growth of the lateral ventricles in preterm infants with real-time ultrasound. Arch Dis Child 1981; 56: 900-4.

- Larroche J-C. Post-haemorrhagic hydrocephalus in infancy. Anatomical studies. Biol Neonate 1972; 20: 287-99.

7 Lorber J, Bhat U S. Post-haemorrhagic hydrocephalus. Diagnosis, differential diagnosis, treatment, and long term results. Arch Dis Child 1974; 49: 751-62.

8 Fitzhardinge P M, Pape K, Arstikaitis M, et al. Mechanical ventilation of infants of less than $1501 \mathrm{~g}$ birth weight: health, growth, and neurologic sequelae. J Pediatr 1976; 88: $531-41$.

9 Naidich T P, Epstein F, Lin J P, Kricheff I I, Hochwald $G$ M. Evaluation of pediatric hydrocephalus by computed tomography. Radiology 1976; 119: 337-45.

10 Krishnamoorthy K S, Fernandez R A, Momose K J, et al. Evaluation of neonatal intracranial hemorrhage by computerized tomography. Pediatrics 1977; 59: 165-72.

11 Rumack C M, McDonald M M, O'Meara O P, Sanders B B, Rudikoff J C. CT detection and course of intracranial hemorrhage in premature infants. $A J R$ 1978; 131 : 493-7.

12 Burstein J, Papile L-A, Burstein R. Intraventricular hemorrhage and hydrocephalus in premature newborns: a prospective study with CT. AJR $1979 ; 132$ : 631-5.

13 Krishnamoorthy K S, Shannon D C, DeLong G R, Todres I D, Davis $K$ R. Neurologic sequelae in the survivors of neonatal intraventricular hemorrhage. Pediatrics 1979; 64: 233-7.

14 Ahmann P A, Lazara A, Dykes F D, Brann A W, Jr,
Schwartz J F. Intraventricular hemorrhage in the high- $\Omega$ risk preterm infant: incidence and outcome. Ann Neurol 1980; 7: 118-24.

15 Bada H S, Salmon J H, Pearson D H. Early surgical $\vec{F}$ intervention in post-haemorrhagic hydrocephalus. Childs $\stackrel{9}{+}$ Brain 1979; 5: 109-15.

16 Deonna T, Payot M, Probst A, Prod'hom L S. Neonatal intracranial hemorrhage in premature infants. Pediatrics $\overline{\bar{\omega}}$ 1975; 56: 1056-64.

17 Deonna T, Calame A, Van Melle G, Prod'hom L S. ¿ Hypoglycorrhacia in neonatal intracranial haemorrhage. Helv Paediatr Acta 1977; 32: 351-61.

18 Volpe J J. Intracranial hemorrhage in the newborn: $\vec{\circ}$ current understanding and dilemmas. Neurology (Minneap) 1979; 29: 632-5.

10 Goldstein G W, Chaplin E R, Maitland J, Norman D. Transient hydrocephalus in premature infants: treatment by lumbar punctures. Lancet 1976 ; i: $512-4$.

20 Epstein F, Hochwald G M, Ransohoft J. Neonatal i hydrocephalus treated by compressive head wrapping. ? Lancet 1973; i: 634-6.

21 Porter F N. Hydrocephalus treated by compressive head ? wrapping. Arch Dis Child 1975; 50: 816-8.

22 Papile L, Burstein J, Burstein R, Koffler H, Koops B L, G Johnson J D. Post-hemorrhagic hydrocephalus in low birth weight infants: treatment by serial lumbar puncture. J Pediatr 1980; 97: 273-7.

23 Milhorat T H, Clark R G, Hammock M K, McGrath P P. Structural, ultrastructural, and permability changes in the ependyma and surrounding brain favoring equilibration in progressive hydrocephalus. Arch Neurol 1970; 22: $397-407$.

24 De $S$ N. A study of the changes in the brain in experd $\vec{\theta}$ mental internal hydrocephalus. J Pathol Bacteriol 1958 62: 197-208.

25 Weller R O, Wiśniewski H, Shulman K, Terry R ES Experimental hydrocephalus in young dogs: histological and ultrastructural study of the brain tissue damage. $J$ Neuropathol Exp Neurol 1971; 30: 613-26.

26 Weller $\mathbf{R} O$, Shulman $K$. Infantile hydrocephalus: clinical, histological, and ultrastructural study of brain damage. $J$ Neurosurg 1972; 36: 255-65.

27 Rowlatt U. The microscopic effects of ventricular dilatation without increase in head size. $J$ Neurosurg $1978 ; 48$ : 957-61.

Correspondence to Dr M I Levene, Department of Paediatrics and Neonatal Medicine, Institute of Child Health, Hammersmith Hospital, Du Cane Road, London W12 OHS.

Received 30 June 1981 